\title{
Dynamic Stress Concentration Factor in the Strip Plate with Fillet
}

\author{
N. Nakayama, M. Ohashi, T. Sano*, S. Horikoshi** and H. Takeishi*** \\ Department of Precision Engineering, Graduate School, Chiba Institute of Technology, \\ 2-17-1 Tudanuma, Narashino City, Chiba Prefecture 275, Japan \\ * Mechanical Engineering Laboratory, A.I.S.T., M.I.T.I., 1-2 Namiki, Tsukuba City, \\ Ibaraki Prefecture 305, Japan \\ **A.E.S., 1-6-1 Takezono, Tukuba City, Ibaraki Prefecture 305, Japan \\ *** Department of Precision Engineering, Chiba Institute of Technology, 2-17-1 Tudanuma, \\ Narashino City, Chiba Prefecture 275, Japan
}

\begin{abstract}
Dynamic and static stress concentration factors $\alpha_{D \max }$ and $\alpha_{S}$ generated at a fillet part are observed by photoelastic method, and the comparison between two different factors is carried out. Next, the reflection coefficient $A$ is calculated using the height of incident and reflected waves measured by the strain gauge. As the result, following relationship $\alpha_{\operatorname{Dmax}}=(1+A) \alpha_{S}$ is derived experimentally. The equation shows that the maximum dynamic stress concentration factor $\alpha_{\text {Dmax }}$ is easily calculated using the static stress concentration factor $\alpha_{\mathrm{S}}$ and the reflection coefficient $A$.
\end{abstract}

Résumé : Les facteurs de concentration de contrainte dynamique $\alpha$ Dmax et statique $\alpha_{\mathrm{S}}$ dans un épaulement sont observés photólastiquement. Ensuite, le coefficient de rétlexion $A$ est calculé en utilisant les hauteurs de vagues incidentes et réfléchies mesurées par jauge à fil résistant. La relation $\alpha_{\mathrm{Dmax}}=(1+A) \alpha_{\mathrm{S}}$ est obtenue expérimentalement. Cette équation montre que le facteur dynamique de concentration de contrainte est facilement calculê en utilisant le facteur statique et le coefficient de réflexion $A$.

\section{INTRODUCTION}

Studies on the stress concentration at the discontinuities such as holes and notches have been done so far ${ }^{[1-3]}$. These studies have provided information under static loading. However, few cases of dynamic loading have been discussed ${ }^{[4][5]}$.

The purpose of this study is then to investigate the behavior of discontinuity under dynamic loading For the purpose, the dynamic stress concentration factor and the reflection coefficient at the fillet are obtained using a square wave. In a previous work, the rising part of the square wave was considered as the dynamic loading, and the plateau of the wave as the static loading on condition that the plateau lasted for long time ${ }^{[6]}$.

The strip with the fillet is one of the basic models of actual structures. When the stress wave travels into another strip plate with bigger cross sectional area, the reflection and the transmission take place due to the difference of acoustic impedance at the fillet part, even if the material of two strips is same.

Static and dynamic photoelastic methods are employed to measure the stress concentration factor. And strain gauge method is used to obtain the reflection coefficient.

\section{EXPERIMENTAL PROCEDUER}

\subsection{Static and dynamic stress concentration factors}

Figure 1 shows the shape of the strip plate with a fillet. The fillet is shown as the shadowed part in the figure. The strip plate is composed of DAP (diallylphtalate), an isotropic phtoelastic resin. In the figure, $\rho, c_{1}$ and $c_{2}$ represent the density and propagation velocities of stress wave in the strip plate I and II respectively, and $\mathrm{E}$ is the Young's modulus. The DAP had the Young's modulus of $3.09 \mathrm{GPa}$, poisson's ratio of 0.39 , and density of $1.21 \times 10^{3} \mathrm{~kg} / \mathrm{mm}^{3}$. The thickness of the plate was $6 \mathrm{~mm}$. The radius 
of the fillet was changed i.e. the value of $\mathrm{r} / \mathrm{B}$ was changed from 0.5 to 2.0 , while the width of plate was kept constant $10 \mathrm{~mm}$.

In the case of the dynamic experiment, the width and the longitudinal length of the plate II were long to be considered as semi-infinite to eliminate the effect of reflection from the plate II

A compressed air gun was used to generate square stress waves. A striker made of acrylic resin had an outer diameter of $10 \mathrm{~mm}$ and an inner diameter of $8 \mathrm{~mm}$, an length of $300 \mathrm{~mm}$, and a hemispherical shell is attached at an tend. The square stress wave with the rising time $\operatorname{Tr}=45 \mu \mathrm{s}$, and a duration $\mathrm{T}=330 \mathrm{ks}$ was generated.

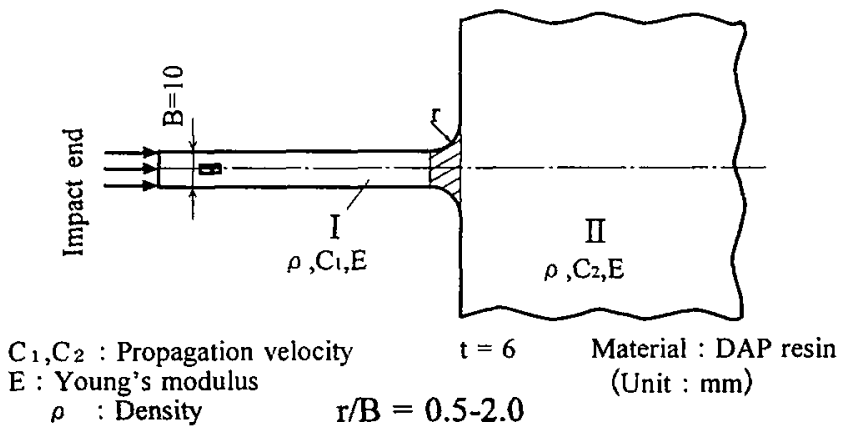

Figure 1: The shape of the strip plate with a fillet

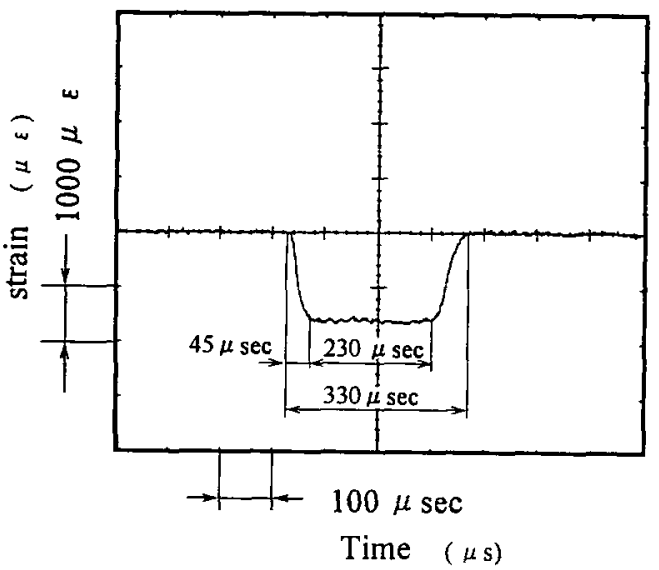

Figure 2: The waveform of the square wave obtained by strain gauge in the strip plate I

Figure 2 shows the waveform of the square stress wave obtained by strain gauge in the strip plate I Cranz-shardin optical system used to record the dynamic fringe patterns was composed of 9 microflash lamps with a flashing time of $1 \mu \mathrm{s}$, and 9 cameras. Examples of dynamic fringe patterns are shown in Figure 3. For the static photoelastic, the conventional method was employed.

In the static experiment, the stress concentration factor is defined by the ratio of the maximum stress $\sigma_{\text {Smax }}$ at the fillet to the nominal stress $\sigma_{\text {so }}$ generated in the plate I .

Static and dynamic stress concentration factors are related to the fringe number as follows:

$$
\begin{aligned}
& \alpha_{\mathrm{S}}=\sigma_{\mathrm{S} \max } / \sigma_{\mathrm{S} 0}=N_{\mathrm{S} \max } / N_{\mathrm{S} 0} \\
& \alpha_{\mathrm{D}}=\sigma(\mathrm{t})_{\mathrm{Dmax}} / \sigma_{\mathrm{D} 0}=N(\mathrm{t})_{\mathrm{Dmax}} / N_{\mathrm{D} 0}
\end{aligned}
$$

In equation (2), the $\sigma(\mathrm{t})_{D_{\max }}$ and the $\sigma_{1 \times}$ are the maximum stress of the fillet and the dynamic nomin:? stress observed without fillet 


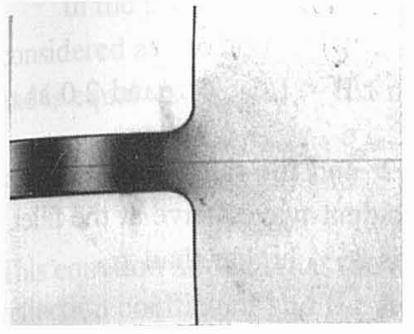

(a) $\mathrm{T}=0 / 1 / \mathrm{s}$

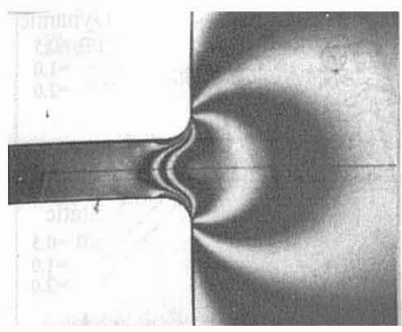

(d) $\mathrm{T}=75 \mu \mathrm{s}$

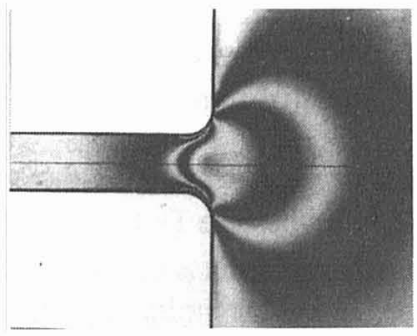

(b) $\mathrm{T}=25 \mu \mathrm{s}$

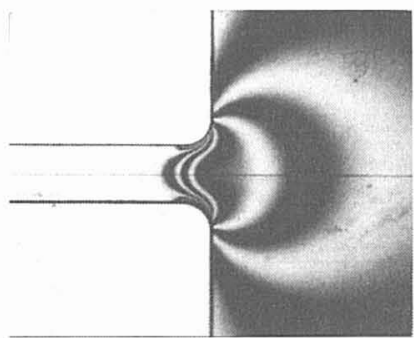

(e) $\mathrm{T}=100 \mu \mathrm{s}$

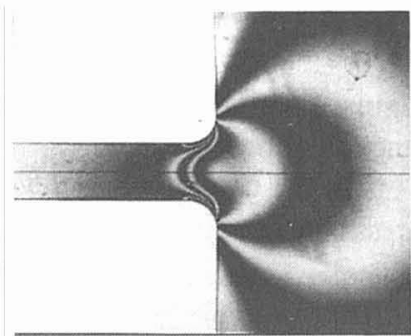

(c) $\mathrm{T}=50 \mu \mathrm{s}$
Figure 3: The photograph of dynamic fringe patterns at the fillet with $\mathrm{r} / \mathrm{B}=0.5$

\subsection{Reflection coefficient}

The reflection coefficient $A$ was calculated to investigate the influence of the reflected wave from fillet on the dynamic stress concentration. The gas gun and the specimen were also used in this experiment. The reflection coefficient $A$ was calculated using the equation

$$
A=\sigma_{\mathrm{R} \max } / \sigma_{\text {Imax }}
$$

As can be seen from the Figure 4 , the $\sigma_{R \max }$ is the height of the plateau of reflected wave, and the $\sigma_{\max }$ is the height of the incident square stress wave.

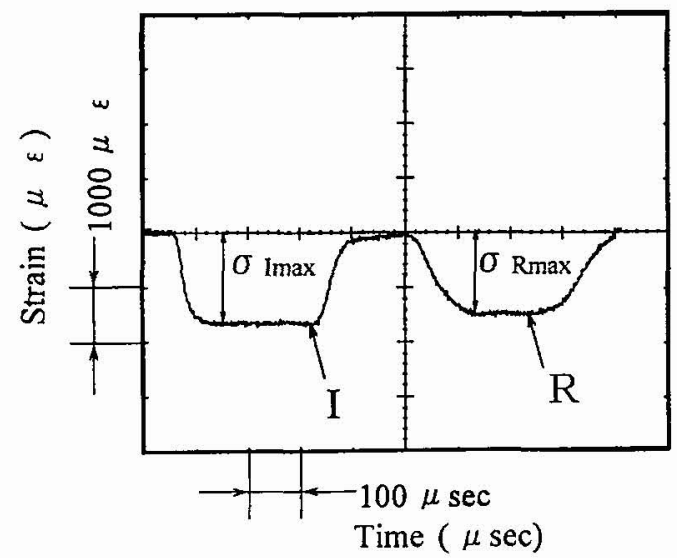

Figure 4: The waveform of the reflected wave from the fillet obtained by strain gauge $(\mathrm{r} / \mathrm{B}=0.5)$ 


\section{RESULTS AND DISCUSSION}

Figure 5 shows the dynamic and static stress concentration at the fillet with $r / B=0.5,1.0$ and 2.0 as a function of time

In the case of $\mathrm{r} / \mathrm{B}=0.5$, the static stress concentration factor was 1.52 , and the maximum dynamic stress concentration factor $\alpha_{D \max }$ was 2.75 at the time $\mathrm{T}=80 \mu \mathrm{s}$ after the incident wave arrive at the fillet, while the $\operatorname{Tr}$ was $45 \mu \mathrm{s}$. The maximum dynamic stress concentration factor is $85 \%$ higher than $\alpha_{\mathrm{s}}$.

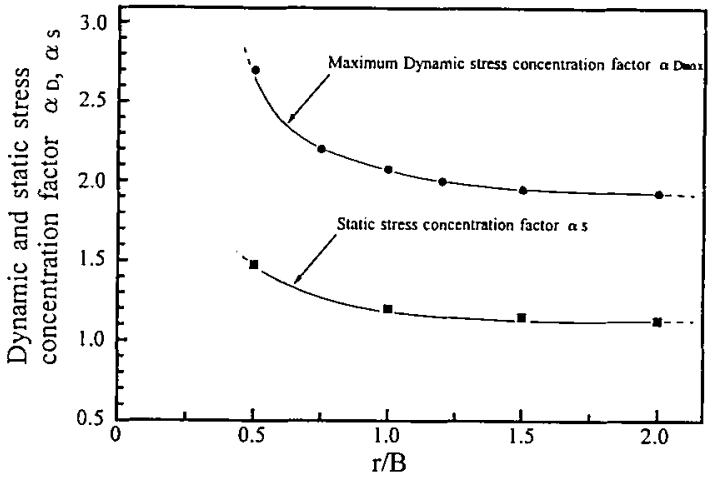

Figure 5: the dynamic and static stress concentration at the fillet as a function of time.

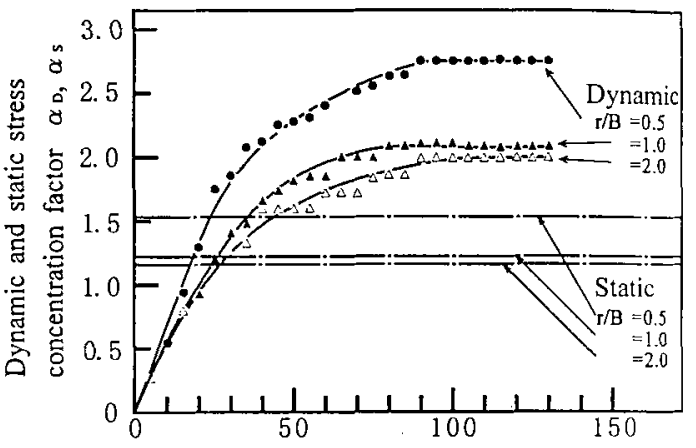

Time after the incident wave arrive at time $(\mu \mathrm{s})$

Figure 6: The relation between the stress concentration factors and the $\mathrm{r} / \mathrm{B}$

The relation between the stress concentration factors and the r/B are shown in Figure 6 . the stress concentration factors $\alpha_{S}$ and $\alpha_{D \max }$ decrease with the increase in $r / B$. The $\alpha_{D \max }$ is $70-90 \%$ higher than the $\alpha_{\mathrm{S}}$, which could be attributed to the duplication of the reflected wave. In general, the dynamic stress concentration factor is nearly equal / lower than static one. However, the opposite result was also reported for the strip plate with discontinuity of a circular hole ${ }^{[5]}$. In such case, the dynamic stress concentration factor was $12 \%$ higher than the static stress concentration factor.

Figure 7 shows the relationship between the reflection coefficient $A$ and $\mathrm{r} / \mathrm{B}$. As can be seen in the figure, the reflection coefficient falls from about 0.7 to 0.9 with the increase in $\mathrm{r} / \mathrm{B}$. The reflection coefficient $\boldsymbol{A}$ is nearly equal to the difference between the $\alpha_{\operatorname{Dmax}}$ and the $\alpha_{\mathrm{S}}$ for the fixed value of r/B

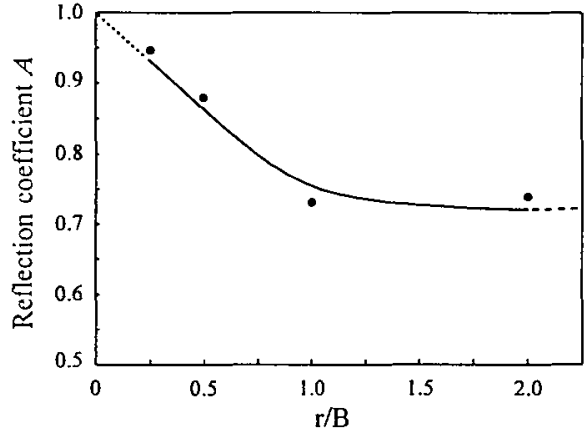

Figure 7: The relationship between the reflection coefficient $A$ and $\mathrm{r} / \mathrm{B}$

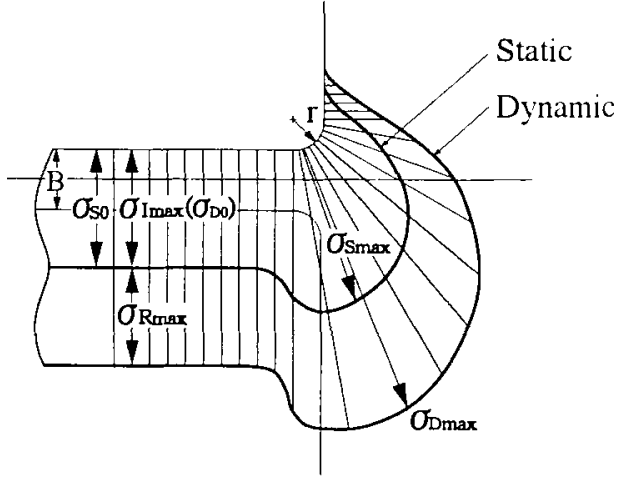

Figure 8: the dynamic and static stress distributions along the free boundary of the fillet

Figure 8 shows the distribution of $\sigma_{D \max }$ along the free boundary of the fillet obtained from Fig. 3(e) together with the static stress distribution. The dynamic stress distributions is similar to the static one. All stresses used in this figure are normalized by nominal stresses. In dynamic photoelastic method. the plateau height of the incident wave $\sigma_{\operatorname{lmax}}$ is the same as nominal stress $\sigma_{D}$. 
In the plate I , the $\sigma_{\text {Imax }}$ and the $\sigma_{\mathrm{Rmax}}$ are superimposed. If the summation of $\sigma_{\mathrm{Imax}}$ and $\sigma_{\mathrm{R} \max }$ are considered as the nominal stress, the dynamic stress concentration factor is given by $\sigma_{\mathrm{D} \max } /\left(\sigma_{\mathrm{Imax}}+\sigma_{\mathrm{R} \max }\right)$, and is equal to the $\alpha \mathrm{s}(=1.5)$. The following equation is obtained.

$$
\sigma_{\text {Dmax }} /\left(\sigma_{\text {Imax }}+\sigma_{\text {Rmax }}\right)=\alpha \mathrm{s}
$$

Substituting the eqs.(2) and (3) into the (4), we obtain

$$
\alpha_{\text {Dmax }}=(1+\mathrm{A}) \times \alpha_{\mathrm{S}} \text {. }
$$

This equation implies that the dynamic stress concentration factor at the fillet could be determined using the reflection coefficient and the static stress concentration factor.

To confirm the validity of the equation above, the comparison between the $\alpha_{D \max }$ obtained directly by dynamic photoelastic method and the $\alpha_{\text {exDmax }}$ calculated by eq.(5) was done. The result is shown in Figure 9. The factor $\alpha_{\text {exDmax }}$ agrees with the factor $\alpha_{\text {Dmax }}$ within the error of $3 \%$.

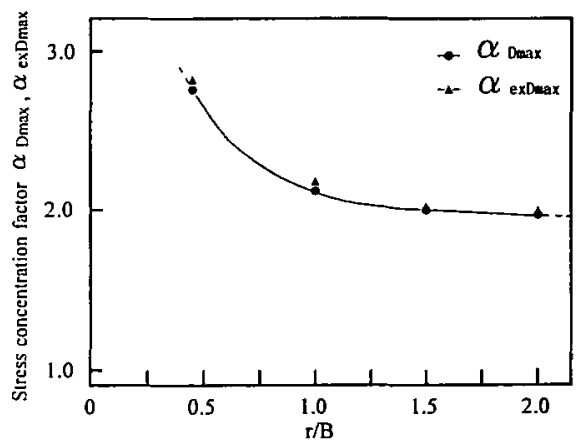

Figure 9: The comparison between the $\alpha_{\operatorname{Dmax}}$ and the $\alpha_{\operatorname{exDmax}}$ as a function of $r / B$

\section{CONCLUSION}

The static and the dynamic stress concentration factors at the fillet was determined by photoelastic methods. And the comparison between them was carried out. Furthermore, the reflection coefficient $A$ was calculated to investigate the influence of reflected wave on the dynamic stress concentration. As a result, the following conclusions are obtained.

1) The dynamic stress concentration factor $\alpha_{\mathrm{D}}$ is $70-90 \%$ higher than static stress concentration factor $\alpha_{\mathrm{s}}$, and decreases with the increase in $\mathrm{r} / \mathrm{B}$.

2) The reflection coefficient $A$ decreases from 0.9-0.7 with the increase in r/B.

3) The maximum dynamic stress concentration factor $\alpha_{D \max }$ in the fillet is determined by the equation, $\alpha_{\operatorname{Dmax}}=(1+A) \times \alpha_{\mathrm{s}}$.

\section{References}

[1] R.E.PETERSON., STRESS CONCENTRATION DESIGN FACTORS (Jonwiley\&Sons,Inc., NewYork, 1965) pp. 59-76.

[2] C.W.BEADLE and H.D.CONWAY, Journal of Applied Mechanics March (1963) 138-140.

[3] M.M.Frocht., PHOTOELASTICITY (Pergamon Press, Oxford, 1961) pp. 169-184.

[4] J.W.Dally and W.F.Halbleib., Journal Mechanical Engineering Science 7 -1 (1965) 23-27.

[5] Richard Shea., Experimental Mechanics 4 (1964) 20-25

[6] K.Kawata and S.Hashimoto., IBID 1 (1965) 69-102. 